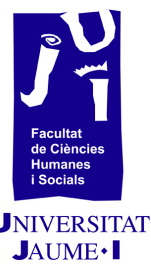

\title{
La influència de la llengua i cultura materna en l'aprenentatge de l'anglés arreu del món
}

Alicia Chabert Alicia.chabert@uji.es 


\section{Resum}

L'ensenyament de l'anglés és indispensable avui dia, tanmateix, els resultat són molt diversos entre centres i regions. No obstant això, de manera general, s'utilitza un enfocament que ha gaudit de molt d'èxit durant molts anys; ens referim a l'ensenyament comunicatiu de la llengua (CLT, per les sigles en anglés), que ha derivat en diversos models innovadors com l'aprenentatge integrat de continguts i llengües estrangeres (AICLE, en anglés Content Language Integrated Learning, CLIL) i l'aprenentatge per tasques. Malgrat l'èxit que ha tingut, aquest model és molt heterogeni, cosa que ha donat una disparitat de resultats entre centres i països. A més a més, aquest enfocament deixa de banda la llengua materna dels alumnes (L1). Nous models multilingües han començat a desenvolupar-se (com ara el model dinàmic multilingüe), però encara no hi ha un consens sobre l'aplicació i utilització de la L1 en l'aula de la segona llengua (L2) i els beneficis que té. Per aquesta raó, la nostra investigació se centra en els beneficis de la utilització de la L1 en l'aprenentatge de llengües i com es pot incloure en el model del CLT. Per tal de demostrar la nostra hipòtesi, hem fet una prova en un col-legi de Castelló de la Plana. Aquesta ha consistit a impartir la mateixa classe d'anglés totalment en anglés en un grup i parcialment en català en un altre. Els resultats obtinguts demostren la nostra teoria i els considerarem per a un estudi més extens a llarg termini per tal d'aconseguir-ne més dades i desenvolupar-ne un nou model educatiu.

Paraules clau: multilingüisme, ensenyament comunicatiu de la llengua, $\mathrm{CLT}$, model dinàmic multilingüe, DMM, llengua materna (L1), interllengua, competència comunicativa, adquisició de llengües, SLA.

\section{Introducció}

Per tal de mostrar la rellevància de la nostra investigació, primerament explorarem breument l'evolució del CLT a la vegada que analitzarem les diferents contribucions de cada metodologia i continuarem amb unes directrius que resumiran l'essència d'aquesta ensenyança. Després d'establir la situació actual del CLT, introduirem un nou enfocament multilingüe i ens centrarem en la situació de la L1 en l'aprenentatge de la L2, en Iloc de considerar L1 com a una unitat independent. La proposta del nostre enfocament es basa en la nostra experiència personal d'ensenyament en diferents països a Europa i Àsia i considerem que l'aplicació d'aquesta serà rellevant per a futures investigacions. Els resultats de la prova pilot duta a 
terme confirmen que l'enfocament multilingüe podria millorar l'aprenentatge de l'anglés com a segona llengua.

\subsection{L'evolució de l'ensenyament comunicatiu}

El tipus de relació entre l'aprenentatge de la segona llengua i la pedagogia ha atret l'atenció de diversos experts al llarg dels anys i s'ha estudiat des de diferents perspectives (Ellis, 1997). No obstant això, la metodologia actual més aclamada és l'ensenyament comunicatiu de la llengua (CLT), que va nàixer a finals dels anys seixanta. En aquell moment, existia una necessitat de centrar-se en l'ensenyament de llengües des d'un punt de vista comunicatiu proficient, més que de l'aprenentatge i el control de les estructures (Richards i Rodgers, 2001). Encara que aquest moviment va començar com una innovació britànica centrada en plans alternatius, el concepte de CLT es va expandir ràpidament de manera global i es considera un enfocament, més que una metodologia, que té com a objecte desenvolupar la competència comunicativa com a objectiu principal de l'ensenyança de llengües i les competències lingüístiques que reconeixen la interdependència entre llengua i comunicació.

L'ensenyament comunicatiu de llengües es va desenvolupar des del concepte de competència comunicativa en 1972, introduït per Hymes en la seua teoria de la competència comunicativa en contrast amb la competència lingüística de Chomsky, que rebutjava la idea que es naixia com una tabula rasa i va introduir-hi la hipòtesi de la gramàtica universal, en la qual les llengües, tan diverses com pareixen superficialment, comparteixen similituds fonamentals que son atribuïbles a principis innats únics de la llengua. La crítica principal de la gramàtica universal en la descripció de l'adquisició de la segona llengua (SLA, per les sigles en anglés) era que no tenia en compte els processos psicològics involucrats en l'aprenentatge de llengües i només se centrava en la competència lingüística. Hymes va incloure l'habilitat d'utilitzar la competència gramatical en una varietat de situacions comunicatives de manera que va portar la perspectiva sociolingüística a la visió purament lingüística de Chomsky.

El model de Hymes (1972) va marcar un abans i un després en la investigació de SLA i es va convertir en la base de l'ensenyament comunicatiu. No obstant això, aquest model tenia defectes. Hymes no va incloure la importància de la interacció de la llengua, que considerem especialment rellevant en una teoria de la comunicació. Canale i Swain (1980) van desenvolupar aquesta teoria amb una simple estructura nova. Van crear un model en el qual van dividir la competència en una llengua en quatre categories: lingüística (gramàtica), sociolingüística (l'ús correcte de la llengua en una situació particular), discurs (I'habilitat de participar en conversacions fluidament i llegir textos difícils) i estratègica (improvisar amb la 
llengua per a un fi específic). L'estructura de Canale i Swain es va utilitzar per a nous models com el de Bachman (1990) o Celce-Murcia (1995). Bachman (1990) afirmava que l'habilitat lingüística comunicativa consistia en el coneixement gramàtic (domini lingüístic) i la manera en què s'utilitza la llengua de manera apropiada en un context comunicatiu. Per tal de comprovar aquesta teoria, Bachman va proposar el seu model en 1990, que va desenvolupar en $1996 \mathrm{i}$ 2010 junt a Palmer.

El model de Bachman i Palmer és un model molt complet per a l'avaluació de la llengua, ja que divideix l'habilitat lingüística en dues àrees àmplies: el coneixement lingüístic (organitzacional i pragmàtic) i la competència estratègica. A més a més, aquest va ser el primer model que va incloure I'habilitat pragmàtica com una categoria i, contràriament al model de Canale (que se centra en el rol de la sociolingüística), se centra en la competència estratègica o els components metacognitius, com s'hi refereix Bachman (1996: 70). Nogensmenys, el model de Bachman i Palmer ha sigut criticat per ser molt teòric i centrar-se principalment en l'avaluació més que en l'ensenyament (Fulcher i Davidson, 2007), així que es converteix en un marc teòric per a l'avaluació del domini lingüístic en lloc de l'enfocament de l'ensenyança.

Celce-Murcia (1995) va reconèixer la mancança d'interacció i interrelació en els models que hem analitzat i els va desenvolupar en un nou model que incloïa la competència accional, que inclou la comprensió de la intenció comunicativa del parlant portant a terme i interpretant els actes de parla.

En aquest model, Celce-Murcia proporciona una extensa visió de les competències lingüístiques i culturals que afecten l'execució de l'ús de la llengua de l'estudiant, en el qual la competència estratègica s'utilitza totalment en les competències comunicatives i de discurs. La competència estratègica és el component principal on totes les competències interactuen. Encara que aquest model mostra la interrelació de competències, se centra principalment en el discurs i assumeix que el domini de la comprensió va lligat a la competència discursiva, encara que no necessàriament han d'estar al mateix nivell, ja que el discurs se centra en la producció i no implica interacció. Celce-Murcia va proposar una revisió d'aquest model en 2000 (Celce-Murcia i Olshtain, 2000), on incloïa les competències interaccional i formulaica.

Aquest model innovador inclou la competència formulaica, que es refereix a aquelles seccions del llenguatge que son fixes i prefabricades, i que els parlants poden utilitzar en interaccions diàries. No obstant això, aquesta competència es podria considerar inclosa dins de la competència estratègica i interaccional, ja que és un ús estratègic de la llengua que consta de competències lingüístiques i socioculturals. La competència interaccional implica el 
coneixement i la utilització de les normes d'interacció en situacions comunicatives dins de la llengua d'una comunitat i una cultura. Les fórmules prefabricades canvien segons el context i la cultura.

Com hem observat, una gran varietat de models de CLT s'han desenvolupat al llarg del temps i alguns d'aquests hi estan relacionats només de manera distant, cosa que demostra la natura eclèctica d'aquest enfocament. Dörnyei (2009) va analitzar les característiques del CLT explorant les diferents interpretacions al llarg dels anys i va proposar una col-lecció de principis que servien com a guia, i que va anomenar enfocament dels principis comunicatius de la llengua (PCA, per les sigles en anglés). Els principis proposats van ser els següents: el principi d'importància personal, que implica que l'ensenyança s'ha de centrar en el significat i ha de tenir un valor personal, és a dir, s'ha de centrar en l'alumne; el principi de pràctica controlada, en la qual es necessiten activitats de pràctica controlades per a promoure l'automatització d'habilitats en L2 i millorar la fluïdesa; el principi d'input declaratiu, amb el qual l'ensenyament ha de contenir components d'input inicial explícits per tal de proporcionar material d'arrancament per a una automatització subseqüent; el principi d'enfocament en la forma, pel qual la classe s'ha d'enfocar en aspectes formals de la L2 que en regulen la precisió i la manera apropiada; el principi de llengua formulaica, en el qual s'inclouen fórmules útils d'aplicació en la comunicació en la vida real; el principi d'exposició a la llengua estrangera, i finalment el principi d'interacció enfocada amb el qual s'ha d'oferir als alumnes una àmplia oportunitat per participar en interaccions genuïnes en $\mathrm{L} 2$ en diferents contextos.

Els principis de Dörnyei recullen les característiques principals del CLT i intenten unificar les idees generals dels diversos models de CLT. Aquests principis intenten oferir guies generals per a implementar un enfocament comunicatiu sense proposar un nou marc teòric. Se centren en la motivació de l'alumne i l'exposició i la comprensió que pareixia haver-se quedat en el rerefons d'altres teories per tal de centrar-se en discurs i producció.

\subsection{La presència de la llengua materna en l'ensenyament comunicatiu}

La presència de la L1 en l'aprenentatge de L2 ha sigut polèmica al llarg de la història de l'ensenyament i l'aprenentatge de llengües estrangeres a causa de la creença en la influència positiva o negativa (segons autors i estudis anteriors) de la primera llengua en la segona, basada en la similitud de les llengües. Tanmateix, el consens general solia ser (i encara sembla que ho és) que la millor manera de desenvolupar la L2 és una immersió completa sense lloc per a la primera llengua a l'aula, malgrat que s'ha demostrat que la interacció facilita l'adquisició de llengües (Gass i Mackey, 2006; Alcón Soler i 
García Mayo, 2009) i que la competència cognitiva de la L1 influeix en I'adquisició de L2 (Upton i Lee-Thompson, 2001).

En aquesta secció explorem la situació de L1 en SLA en l'actualitat i farem el possible per demostrar la necessitat d'integrar la primera llengua en l'aprenentatge de segona llengua des d'un punt de vista teòric abans de demostrar empíricament els beneficis d'usar la primera llengua a l'aula.

Després d'analitzar enfocaments de CLT molt diferents i influents en la perspectiva de l'ensenyament actual, observem que la L1 no es s'hi té en compte i, en general, el disseny dels plans d'estudi no consideren que els estudiants ja posseeixen coneixements lingüístics (Swan, 1985). En referir-se a l'adquisició de L1 a l'aula de L2, veiem que la recerca s'ha centrat principalment en l'ús de L1 a I'aula de L2 i la influència de L1 en l'aprenentatge L2. Aquesta recerca se centra en fenòmens com la interllengua, la transferència lingüística, la influència intercultural $i$, en estudis més recents, el model dinàmic multilingüe.

La qüestió sobre si la L1 s'hauria d'utilitzar a les aules de L2 s'ha discutit extensament i encara és un debat dins de la comunitat de recerca. La raó principal per no utilitzar la L1 és que els estudiants estiguen tan exposats com siga possible a la L2, per tal que l'aprenguen amb èxit. Hi ha molta evidència que recolza el fet que la quantitat (a més de la qualitat) de l'aprenentatge de la llengua estrangera és necessària en l'aprenentatge de L2 (Krashen i Terrell, 1983; Ellis, 1997; Willis, 1996), tot i que sovint es confon amb l'absència absoluta de la L1 a l'aula.

D'altra banda, altres investigadors (Cook, Long i McDonough, 1979) han assenyalat el fet que una primera llengua no és simplement una qüestió d'aprenentatge de sintaxi i vocabulari; sinó que és ambiental, lingüística i emocional, i que ignorar la L1 disminuirà el nivell cognitiu de l'alumne. No obstant això, hi ha una creença popular entre els professors que l'ús de la L1 és perjudicial per a l'aprenentatge de L2, però «la L1 i L2 coexisteixen en la mateixa ment, ambdues llengües es poden utilitzar simultàniament sense necessitat de convertir trossos d'una en trossos de l'altra» (Cook, 2001: 417). Cook (2001) fa referència a diferents estudis que donen suport a l'evidència dels beneficis d'utilitzar la L1 a l'aula de L2 i demostren que el resultat depén de com s'utilitza la L1. Si ens basem en la bibliografia revisada, podem concloure que és important aconseguir-hi un equilibri, de manera que la L1 no es pot ignorar, però no s'hauria d'utilitzar excessivament a les aules per no obstaculitzar les possibilitats de pràctica de L2.

\subsection{La influència de la $L 1$ en l'aprenentatge de $L 2$}

El paper de la influència lingüística i la transferència en I'adquisició de segones llengües ha estat àmpliament investigat en 
les últimes dècades (Ellis, 1997; Larsen-Freeman i Long, 1991; Odlin, 1989; Selinker, 1972), cosa que mostra tant els efectes positius com els negatius d'aquest fenomen. Odlin descriu el concepte de transferència com "la influència derivada de similituds i diferències entre la llengua estrangera i qualsevol altre idioma que s'haja adquirit prèviament (i pot ser imperfecte)» (Odlin, 1989: 27). Bardovi-Harlig i Sprouse (2017) defineixen el concepte de transferència negativa com la influència de L1 que condueix a errors en l'adquisició o l'ús de la L2, i la transferència positiva com la influència de $\mathrm{L} 1$ que condueix a "adquisició o ús immediata o ràpida de la llengua d'arribada». Tot i que hi ha hagut investigacions sobre les dues consideracions, encara $n$ 'hi ha una gran quantitat sobre la influència lingüística entre influències negatives en comparació amb les positives (O'Neill, Bennett i Vanier, 2010).

Una de les preocupacions principals amb la influència de la $\mathrm{L} 1$ ha estat la «interllengua», terme creat per Selinker en 1972 que fa referència als "errors» (com ara expressions inadequades, interferències o sobregeneralització) adquirits a l'hora d'aprendre una segona llengua, que sorgeixen en la parla de la segona llengua de l'alumne i que tenen el potencial de "fossilitzar-se» congelant-se en la interllengua de la segona llengua d'aprenents. McLaughlin (1987) va concloure que, si bé la L1 afecta el desenvolupament de la interllengua, la influència d'aquesta no sempre és previsible (McLaughlin, 1987).

Malgrat els diferents punts de vista sobre la influència interlingüística, s'ha demostrat en nombrosos estudis que la interacció entre els sistemes lingüístics en un parlant multilingüe desenvolupa un alt nivell de consciència dels idiomes (Jessner, 2006). Com veiem, la L1 no només influeix en l'aprenentatge de L2 pel que fa a la llengua, sinó que també proporciona una consciència metalingüística i pragmàtica. Per tant, podem afirmar que la L1 contribueix al procés cognitiu de la $L 2$, en lloc d'interferir amb l'adquisició de L2 tal com s'havia pensat anteriorment. Com Ellis afirma (1994: 343) «mentre que per als conductistes [la influència de la L1] es va veure com un impediment (causa d'errors), per als cognitius es considera un recurs que l'alumne utilitza activament en el desenvolupament de la interllengua». Ellis proposa que la L1 s'utilitze tant en la comunicació de L2 com en l'aprenentatge, és a dir, que el sistema de L1 utilitze la construcció d'hipòtesis responsable del desenvolupament de la interllengua, així com en els mecanismes de comprensió i producció de la llengua.

Herdina i Jessner (2002) unifiquen la idea d'influència translingüística i d'ensenyament del llenguatge en el seu model dinàmic del multilingüisme (en endavant, DMM per les sigles en anglés), que consideren que "podria servir com un vincle perdut entre l'educació lingüística i la lingüística en el desenvolupament de 
nous conceptes didàctics» (Herdina i Jessner 2002: 159). El DMM proposa que l'adquisició de dues llengües condueix a mètodes específics que influeixen en els processos d'adquisició de llenguatges i, per tant, els autors recomanen que la instrucció del metaconeixement forme part de l'educació lingüística. Des d'aleshores, s'ha esdevingut un auge de l'estudi de la consciència metalingüística i pragmàtica dels estudiants d'idiomes estrangers (Portolés Falomir, 2015; de Angelis, Jessner i Kresic, 2015, de Bot i Jaensch, 2015; Alcón Soler i Martínez Flor, 2008; Alcón Soler i Safont Jordà, 2007), que s'ha convertit en un enfocament innovador del multilingüisme.

\section{Objectiu: proposta d'un enfocament multilingüe en l'ensenyament comunicatiu de la llengua}

Tot i que hi ha hagut un augment dels estudis de recerca sobre consciència pragmàtica i multilingüisme, encara hi ha una clara separació entre els enfocaments de l'ensenyament de llengües i la interacció multilingüe. Com afirma Cook (2010: 156), «des del mètode directe a l'aprenentatge basat en tasques, l'ensenyament de llengües ha insistit en una situació simulada de la segona llengua en què la primera llengua no té cap component». Per aquest motiu, a partir de la nostra experiència personal, així com en les consideracions $\mathrm{i}$ els marcs teòrics revisats anteriorment, observem una clara necessitat d'un enfocament pràctic en què es considere la L1 per a l'aprenentatge de L2. Per resoldre la confusió i el debat generalitzats sobre l'enfocament de l'ensenyament comunicatiu de la llengua i la seva implementació curricular, hem realitzat una prova pilot en un centre escolar de Castelló de la Plana.

Com hem analitzat anteriorment amb la teoria revisada, la L1 és una eina útil que s'hauria d'aprofitar en l'adquisició de L2. L'ús de L1 a les aules de llengua comunicativa es pot utilitzar com a estratègia en totes les parts de la instrucció i l'aprenentatge de L2.

$\mathrm{Hi}$ ha una àmplia investigació i evidència que diferents aspectes de la $L 1$ es poden usar en l'aprenentatge de L2, fins i tot quan els dos idiomes són diferents, com la relació entre les formes de la paraula L1 i L2 i els conceptes de la ment dels aprenents de L2 (Kroll i De Groot, 2005), la relació de contingut semàntic entre L1 i L2 (Jiang, 2002) o la relació fonètica entre L1 i L2 (Barrios, Jian i Idsardi, 2016). Pel que fa a l'evidència i la literatura revisada, considerem que, depenent de la L1 de l'alumne, el professor hauria d'adaptar-hi la instrucció L2. En el nostre estudi, hem comparat l'anglés amb el català en estructura i hem utilitzat la nostra llengua materna per a explicar conceptes gramaticals.

En aquest estudi demostrem els beneficis de l'ús de la L1 com a filtre per a l'aprenentatge de la L2. Específicament, els nostres 
objectius han sigut demostrar que la utilització de la llengua materna

a la classe d'anglés beneficia l'assimilació i l'aprenentatge d'estructures gramaticals. Els nostres resultats confirmen la nostra hipòtesi.

\section{Material i mètode}

La nostra prova pilot forma part d'un estudi de doctorat, per al qual estem fent una investigació a gran escala amb un collegi a Trondheim (Noruega), un a Seul (Corea) i quatre a Castelló (Espanya). L'objectiu d'aquesta prova ens ha servit per a posar en pràctica les activitats preparades per a demostrar les nostres hipòtesis. Per a la mostra de la nostra investigació doctoral estudiarem 240 estudiants: 160 alumnes a Espanya ( 2 classes de 20 alumnes cadascuna de quatre escoles diferents de Castelló), 40 alumnes de Corea del Sud (2 classes de 20 alumnes d'una escola de Seül) i 40 estudiants a Noruega ( 2 classes de 20 estudiants d'una escola de Trondheim). No obstant això, per a la prova pilot comparem les 2 classes d'una de les escoles, en què hem utilitzat la llengua materna en una i només anglés en l'altra.

\subsection{Els participants en l'estudi}

Quant a la selecció dels subjectes d'investigació, durant el curs 2016-2017 vam visitar diversos centres escolars a Castelló per demanar-los la seua col·laboració. Afortunadament, quatre centres hi estaven interessats $i$, d'aquests quatre, un en particular tenia més disponibilitat per observar les classes i participar en la prova pilot (el CEIP Mestre Vicent Artero). Hem optat per estudiar l'alumnat entre 10 i 11 anys en l'últim curs de primària. Aquesta edat en particular va ser escollida per a l'estudi perquè els alumnes ja posseeixen un fonament de la llengua anglesa i es pot observar més ràpidament i clar l'impacte de la metodologia d'ensenyament.

Les dues classes seleccionades van ser sisé $A$ i sisé $B$, de 25 alumnes cadascuna. Tanmateix, no tots els alumnes hi estaven presents en la prova: 20 alumnes es van presentar en sisé $A$ i 21 en sisé B.

\subsection{Preparació de la prova}

Per tal de preparar la prova, ens vam reunir primerament amb la mestra dels alumnes a principis de novembre de 2017, que ens va explicar la seua metodologia d'ensenyament i el contingut i material que utilitza a l'aula. La mestra ens va confirmar que fa servir un enfocament comunicatiu en el qual l'objectiu es fer que l'alumnat parle $\mathrm{i}$ assolisca les estructures gramaticals $\mathrm{i}$ vocabulari que es proposen en el llibre. 
En el moment de la reunió, la mestra ens va comentar el que havien vist a classe i vam sol-licitar observar una de les classes per veure en temps real el nivell de l'alumnat, l'actitud i la dinàmica de la classe.

\subsubsection{Observació de la classe}

Vam observar la classe de 6é B dues setmanes abans de la nostra prova i vam analitzar-hi l'estructura. Primerament, els deures de la classe anterior es van corregir i la mestra va preguntar dubtes sobre les tasques. En aquest moment vam observar que aquests alumnes en particular eren respectuosos i responien positivament a preguntes i tasques. Es va introduir el tema del passat simple regular en anglés i la mestra va donar molts exemples en anglés amb gestos i repeticions de manera que els alumnes havien de deduir-ne l'ús dels exemples proporcionats. En aquest punt, la mestra va portar a terme un enfocament d'ensenyament implícit de la gramàtica. Aquest, dins de l'ensenyament comunicatiu, va ser investigat i desenvolupat primerament per Krashen en 1972, que apostava per un ensenyament completament implícit per a aprendre la llengua, segons afirmava, de manera natural.

Per tal d'ajudar als alumnes a utilitzar el passat simple en frases, la mestra va proporcionar una comunicació contextual integrada, és a dir, va utilitzar imatges, gestos i pistes perquè l'alumnat poguera respondre a les preguntes en passat. Per continuar assolint aquesta gramàtica nova en anglés, van llegir un còmic de Picasso. Aquesta activitat era del llibre, que necessita també la utilització de tecnologia. Els alumnes veien el còmic animat en la pantalla de la classe i a la vegada escoltaven un àudio que llegia la història. Després de fer aquesta activitat, que va durar gairebé tota la classe, la mestra va demanar als alumnes que identificaren les paraules en passat simple en la lectura i va finalitzar la classe.

Després de l'observació de la classe, vam concloure que els alumnes responen bé a lectures, identificació de paraules, utilització de recursos tecnològics i exemples per a deducció. Com que els alumnes estaven estudiant el passat simple, la mestra en va demanar fer l'activitat en passat simple amb el verb to be, ja que els alumnes estaven estudiant el passat però només els verbs regulars i introduir un concepte nou dins d'aquest tema ens permetria utilitzar dos enfocaments diferents a cada aula i veure'n més clarament el resultat.

\subsubsection{La prova}

Vam dissenyar la prova basada en el passat simple del verb to be, que els alumnes van haver de completar després de la nostra 
explicació gramatical. La prova va consistir en la transició del present al passat en oracions i la creació de preguntes en passat:

\section{PAST SIMPLE}

\section{Activities}

1. Write the sentences in past simple / Escriu aquestes oracions en passat simple.

- Yolanda isn't your best friend.

- Julian and his sister are very intelligent.

- The trees are very high.

- My English teacher isn't Scottish.

- Diana's parents are on holiday in Belgium.

2. Write questions to these answers / Escriu les preguntes per a aquestes respostes.

1. Martha was fifteen years old.

2.

No, the teacher wasn't Italian.

3.

The girls were in the garden

4.

Yes, her husband was a doctor

\subsection{La classe i el material}

La classe va constar de les següents parts:

- Part 1 - Introducció per part de la mestra i recol-lecció de deures de la classe anterior (10 min.)

- Part 2-Revisió del passat simple comparant amb el present simple (comparació en la pissarra amb columnes d'ahir i avui) (5 min.)

- Part 3 - Introducció del verb to be en passat simple (català o anglés segons la classe) (10 min.)

- Part 4-Activitats amb targetes amb imatges (15 min.)

- Part 5-Realització de la prova (10 min.)

Després de la introducció i d'arreplegar tots els deures, vam passar a revisar el passat simple comparant amb el present simple en verbs regulars. Els estudiants eren capaços d'identificar si un verb era passat o present segons l'acabament de la paraula (-ed), fet que va ser comú en ambdues classes. Seguidament vam escriure el verb to be en passat a la pissarra i vam explicar com utilitzar-lo en oracions afirmatives, negatives i interrogatives. En una classe (6é B) l'explicació va ser en anglés i a l'altra (6é A) en català. 


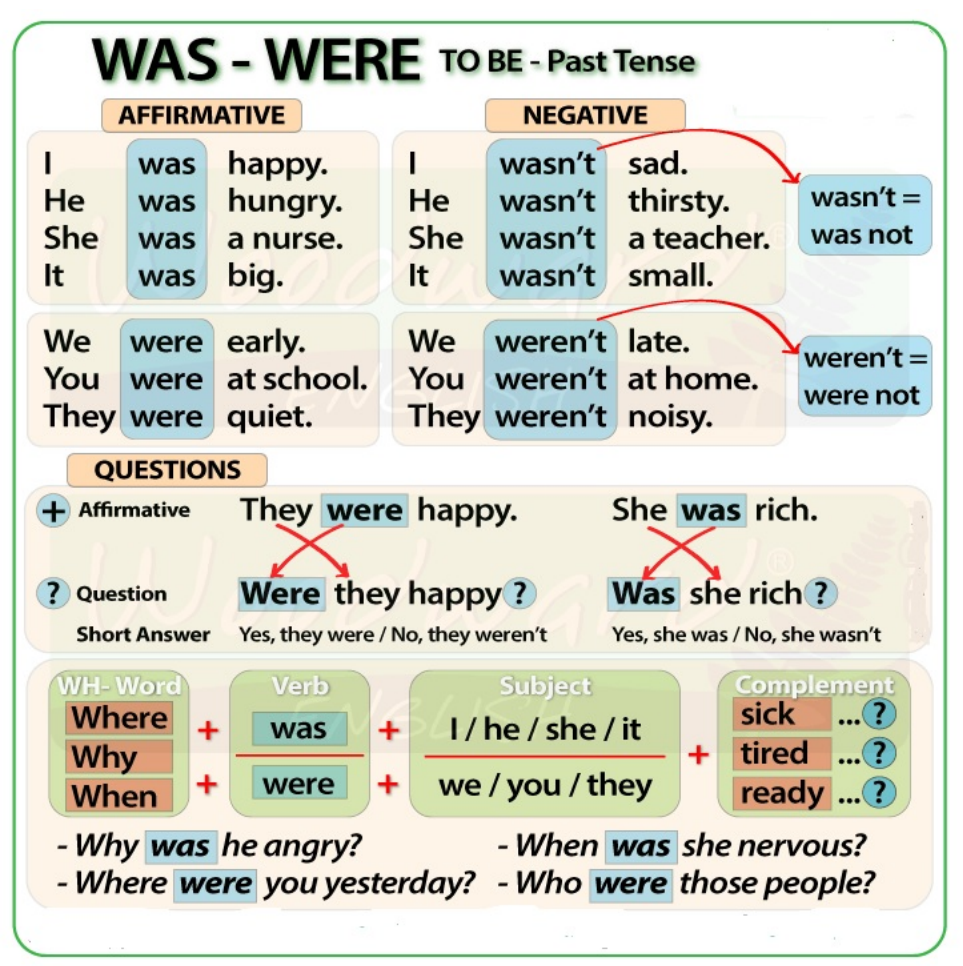

Figura 1. Explicació del verb To be

Per tal de practicar la utilització del passat, vam repartir targetes amb imatges per tota la classe. Els alumnes havien de descriure les imatges utilitzant el passat simple del verb to be com per exemple: They were in the kicthen, he was in school, she was in the restaurant...

Amb l'ajuda de les imatges, en diverses targetes vam utilitzar preguntes tancades en passat i també vam introduir-hi el passat continu, de tal manera que emfatitzàvem la diferència entre was i were. Després de practicar amb jocs, vam realitzar la prova, per a la qual els alumnes no tenien permés parlar entre ells. Durant aquesta, havien de proporcionar informació personal com l'edat, Ilengua materna a casa, nacionalitat i curs.

Els fulls amb la prova completada pels alumnes es van arreplegar al final de la classe. La prova conté 9 preguntes i l'hem puntuada sobre 9.

\section{Resultats}

En el nostre estudi, hem utilitzat un enfocament principalment qualitatiu, ja que hem analitzat la literatura i les teories rellevants, hem observat les classes d'anglés i entrevistat els professors. No obstant això, el nostre article se centra en els resultats de la prova pilot que forma part de la nostra investigació. Els resultats obtinguts es comparen per alumne $\mathrm{i}$ en total amb les dues classes i els 
analitzem quantitativament, així com qualitativament. A continuació presentem els resultats:

Taula 1. Classe impartida en anglés

\begin{tabular}{|c|c|c|c|c|c|c|}
\hline Nom alumne & Sexe & Edat & Curs & Nacionalitat & L1 & Resultat \\
\hline Artero, Bianca & $\mathrm{F}$ & 11 & $6 B$ & Espanya & ES & 1 \\
\hline Aznar, Natalia & $\mathrm{F}$ & 11 & $6 \mathrm{~B}$ & Espanya & ES & 8 \\
\hline Belgoure, Suha & $\mathrm{F}$ & 11 & $6 \mathrm{~B}$ & Marroc & AR/ES & 2 \\
\hline Bellés, Abril & $\mathrm{F}$ & 10 & $6 \mathrm{~B}$ & Espanya & CA/ES & 9 \\
\hline Clavijo, Juan Pablo & M & 11 & $6 \mathrm{~B}$ & Espanya & ES & 3 \\
\hline Corella, Pablo & M & 11 & $6 \mathrm{~B}$ & Espanya & CA/ES & 7 \\
\hline Enrique, Andrea & $\mathrm{F}$ & 11 & $6 B$ & Espanya & ES & 1 \\
\hline Espada, Marc & M & 10 & $6 \mathrm{~B}$ & Espanya & ES & 0 \\
\hline Haddad, Rayan & $\mathrm{F}$ & 10 & $6 \mathrm{~B}$ & Marroc & AR/ES & 4 \\
\hline Huang, Shiman & $\mathrm{F}$ & 11 & $6 \mathrm{~B}$ & Xina & CN/ES & 6 \\
\hline Martínez, Javier & M & 10 & $6 \mathrm{~B}$ & Espanya & CA/ES & 7 \\
\hline Monfort, Alba & $\mathrm{F}$ & 11 & $6 \mathrm{~B}$ & Espanya & ES & 4 \\
\hline Monton, Mireya & $\mathrm{F}$ & 11 & $6 \mathrm{~B}$ & Espanya & ES & 5 \\
\hline Morillo, Agustín & M & 11 & $6 \mathrm{~B}$ & Espanya & ES & 9 \\
\hline Muñoz, Óscar & M & 11 & $6 \mathrm{~B}$ & Espanya & ES & 5 \\
\hline Navarro, Jose Miguel & M & 12 & $6 \mathrm{~B}$ & Espanya & ES & 2 \\
\hline Núñez, Ferran & M & 11 & $6 \mathrm{~B}$ & Espanya & ES & 0 \\
\hline Redac, Lusia Maria & $\mathrm{F}$ & 10 & $6 \mathrm{~B}$ & Romania & RO/ES & 2 \\
\hline Sánchez, Ainara & $\mathrm{F}$ & 10 & $6 \mathrm{~B}$ & Espanya & ES & 5 \\
\hline Saura, Alejandro & M & 11 & $6 \mathrm{~B}$ & Espanya & ES & 0 \\
\hline Sousa, Ana Maria & $\mathrm{F}$ & 12 & $6 \mathrm{~B}$ & Espanya & ES & 0 \\
\hline
\end{tabular}


Taula 2. Classe impartida en català

\begin{tabular}{|c|c|c|c|c|c|c|}
\hline Nom alumne & Sexe & Edat & Curs & Nacionalitat & L1 & Resultat \\
\hline Adell, Natalia & $\mathrm{F}$ & 11 & $6 \mathrm{~A}$ & Espanya & CA & 7 \\
\hline Akhtar, Nabeel & $\mathrm{F}$ & 11 & $6 \mathrm{~A}$ & Paquistan & UR & 8 \\
\hline Auñon, Maria & $\mathrm{F}$ & 11 & $6 \mathrm{~A}$ & Espanya & CA/ES & 7 \\
\hline Cretu, Claudia & $\mathrm{F}$ & 10 & $6 \mathrm{~A}$ & Romania & RO/CA & 8 \\
\hline Cretu, Maria Selena & $\mathrm{F}$ & 11 & $6 \mathrm{~A}$ & Espanya & RO & 1 \\
\hline Cueto, Pau & $\mathrm{M}$ & 11 & $6 \mathrm{~A}$ & Espanya & ES & 9 \\
\hline Espada, Nuria & $\mathrm{F}$ & 11 & $6 \mathrm{~A}$ & Espanya & CA & 2 \\
\hline García, Hugo & $\mathrm{M}$ & 11 & $6 \mathrm{~A}$ & Espanya & ES & 7 \\
\hline García, Lucia & $\mathrm{F}$ & 12 & $6 \mathrm{~A}$ & Espanya & ES & 0 \\
\hline García, Samuel & $\mathrm{M}$ & 10 & $6 \mathrm{~A}$ & Espanya & CA & 3 \\
\hline Martínez, Naomi & $\mathrm{F}$ & 12 & $6 \mathrm{~A}$ & Espanya & ES & 0 \\
\hline Navarro, Arnau & $\mathrm{M}$ & 11 & $6 \mathrm{~A}$ & Espanya & CA & 6 \\
\hline Neagu, Juan Alexandru & $\mathrm{M}$ & 12 & $6 \mathrm{~A}$ & Romania & RO & 0 \\
\hline Necula, Ana Maria & $\mathrm{F}$ & 11 & $6 \mathrm{~A}$ & Espanya & ES & 4 \\
\hline Pons, Carmen & $\mathrm{F}$ & 11 & $6 \mathrm{~A}$ & Espanya & ES & 7 \\
\hline Prades, Enric & $\mathrm{M}$ & 11 & $6 \mathrm{~A}$ & Espanya & CA & 9 \\
\hline Qiu Liu, Liya & $\mathrm{F}$ & 10 & $6 \mathrm{~A}$ & Xina & CN & 8 \\
\hline Salazar, Aarón & $\mathrm{M}$ & 12 & $6 \mathrm{~A}$ & Espanya & CA & 1 \\
\hline Tena, Judit & $\mathrm{F}$ & 11 & $6 \mathrm{~A}$ & Espanya & CA & 8 \\
\hline Vázquez, Ángela & $\mathrm{F}$ & 11 & $6 \mathrm{~A}$ & Espanya & ES & 6 \\
\hline
\end{tabular}

Puntuació total de la classe: 101

Com observem en les taules, malgrat que una de les classes (6é B) tenia un alumne més, l'altra classe (6é A) aconsegueix una puntuació total més alta. En total, la diferència entre donar la classe en català o en anglés és de 21 punts a favor de la classe en català.

Des del punt de vista multilingüe i partint de la base que tots els alumnes son bilingües en català i espanyol, part dels nostres objectius era observar si els alumnes multilingües que parlaven 3 llengües o més (com ara romanés o àrab) obtenien una puntuació més alta. Tanmateix, vam descobrir que els resultats no eren significatius, ja que entre els alumnes multilingües hi havia notes molt altes o molt baixes i no tenim una mostra prou elevada per concloure si hi ha alguna diferència amb els alumnes bilingües.

Contràriament a l'enfocament monolingüe que avalen investigadors com Selinker o Krashen, i que es recomana actualment des del Ministeri, els resultats obtinguts proven que la llengua materna s'hauria de tenir en compte a l'hora d'aprendre'n una de nova.

\section{Discussió i conclusions}

Després de l'anàlisi de l'enfocament comunicatiu actual i de la visió de la L1 en l'aula de L2, observem que les metodologies encara se centren en un enfocament monolingüe independent de la L1 de 
l'alumne i només en els últims anys la L1 s'ha començat a considerar part de l'aprenentatge de $L 2$. Tot i que aquestes noves teories són un gran avanç en la recerca d'adquisició de L2, encara no tenen aplicació en metodologies docents. "L'alumne de FL ha de basar-se en les habilitats $\mathrm{i}$ els coneixements existents adquirits per mitjà de la llengua materna» (Butzkamm, 2003: 31). Per això considerem imprescindible revisar l'enfocament comunicatiu existent, i que s'adapte als estudiants i aprofitar al màxim la seua llengua materna, prenent-la com a base de referència. La nostra prova i actual investigació demostren aquesta teoria.

En la nostra investigació, a banda dels resultats quantitatius, hem analitzat des d'un punt de vista qualitatiu les respostes de l'alumnat per tal de descobrir els errors més comuns i hem arribat a les conclusions següents:

- La majoria dels alumnes amb puntuació baixa tenen dificultat en diferenciar was i were (singular i plural).

- La dificultat més comuna és en l'activitat d'escriure la pregunta d'una resposta, de la qual cosa deduïm que tenen més dificultat a l'hora de canviar l'estructura de l'oració, com ocorre amb les interrogatives.

- Gé A és una classe amb un nivell d'anglés general més baix que 6é $B$, no obstant això, i malgrat tenir un alumne menys, la classe de 6é $A$ ha obtingut una puntuació visiblement més alta, cosa que demostra els beneficis de l'ús de la llengua materna.

Finalment, i com a reflexions concloents, voldríem plantejar el fet que, amb l'aparició de l'anglés com a llengua global, ara més que mai, la presència de L1 esdevé més significativa com a punt de referència per a aprendre un altre idioma. Cal comprendre que L1 serà sempre una eina per aprendre'n d'altres i que facilitarà la nostra comunicació, fins i tot en un idioma diferent. La L2 no s'hauria d'entendre com una llengua completament independent que vol substituir la llengua materna, sinó com una nova eina construïda sobre els fonaments de l'antiga.

\section{Bibliografia}

de Angelis, Gessica, Ulrike Jessner i Marijana Kresic. 2015. Crosslinguistic Influence and Crosslinguistic Interaction in Multilingual Language Learning. Nova York: Bloomsbury Academic.

Atkinson, David. 1987. "The Mother Tongue in the Classroom: a Neglected Resource?». ELT Journal 41 (4): 241-247.

Alcón Soler, Eva, i Maria Pilar Safont Jordà, ed. 2007. Intercultural Language Use and Language Learning. Dordrecht: Springer. 
Alcón-Soler, Eva, i María Pilar García Mayo. 2009. «Introduction». International Review of Applied Linguistics in Language Teaching 47 (3-4): 239. doi: 10.1515/iral.2009.010.

Alcón Soler, Eva, i Alicia Martínez Flor, ed. 2008. Investigating Pragmatics in Foreign Language Learning, Teaching and Testing. Bristol: Multilingual Matters.

Bachman, Lyle F. 1990. Fundamental Considerations in Language Testing. Òxford: Oxford University Press.

Bachman, Lyle F., i Adrian S. Palmer. 1996. Language Testing in Practice: Designing and Developing Useful Language Tests. Oxford: Oxford University Press.

Bardovi-Harlig, Kathleen, i Rex A. Sprouse. 2017. «Negative Versus Positive Transfer». En The TESOL Encyclopedia of English Language Teaching, editat per John I. Liontas. Hoboken, NJ: John Wiley \& Sons.

Barrios, Shannon, Nan Jiang i William J. Idsardi. 2016. "Similarity in L2 Phonology: Evidence from L1 Spanish late-learners' perception and lexical representation of English vowel contrasts». Second Language Research 32 (3): 367-395. doi: $10.1177 / 0267658316630784$.

de Bot, Kees, i Carol Jaensch. 2015. "What is special about L3 processing?» Bilingualism: Language and cognition 18 (2): 130144.

Brown, H. Douglas. 2000. Principles of Language Learning and Teaching. 4a ed. White Plains, NY: Addison Wesley Longman.

Brumfit, Christopher. 1984. Communicative Methodology in Language Teaching: The Roles of Fluency and Accuracy. Cambridge: Cambridge University Press.

Butzkamm, Wolfgang. 2003. "The Language Learning Journal We Only Learn Language Once. The Role of the Mother Tongue in FL Classrooms: Death of a Dogma». Language Learning Journal 28: 29-39.

Canale, Michael. 1983. «From Communicative Competence to Communicative Language Pedagogy». En Language and Communication, editat per Jack C. Richards i Richard W. Schmidt, 2-27. Londres: Longman.

Canale, Michael, i Merrill Swain. 1980. «Theoretical bases of communicative approaches to second language teaching and testing». Applied Linguistics 1 (1): 1-47. 
Celce-Murcia, Marianne. 1995. «Communicative Competence: A Pedagogically Motivated Model with Content Specifications». Issues in Applied Linguistics 6: 5-35.

—. 2007. «Rethinking the Role of Communicative Competence in Language Teaching». En Intercultural Language Use and Language Learning, editat per Eva Alcón Soler i M. Pilar Safont Jordà, 41-57. Dordrecht: Springer.

Celce-Murcia, Marianne, i Elite Olshtain. 2000. Discourse and Context in Language Teaching: A Guide for Language Teachers. Cambridge: Cambridge University Press.

Chomsky, Noam. 1965. Aspects of the Theory of Syntax. Cambridge: M.I.T. Press.

Cook, Vivian. 2001. «Using the First Language in the Classroom». The Canadian Modern Language Review 57 (3): 402-423. doi: 10.3138/cmlr.57.3.402.

- 2010. "The Relationship between First and Second Language Acquisition». En Continuum Companion to Second Language Acquisition, editat per Ernesto Macaro, 137-157. Londres: Continuum.

Cook, Vivian, John Long, i Steven McDonough. 1979. "First and Second Language Learning». En The Mother Tongue and Other Languages in Education, National Congress on Languages in Education (Great Britain), editat per George E. Perren, 7-22. Durham: Centre for Information on Language Teaching and Research.

Dąbrowska, Ewa. 2015. «What Exactly Is Universal Grammar, and Has Anyone Seen It?» Frontiers in Psychology 6: 1-17. doi: 10.3389/fpsyg.2015.00852.

Dörnyei, Zoltán. 2009. "The 2010s Communicative Language Teaching in the 21st Century». 34th National Convention of TESOL, 33-42.

Ellis, Nick C. 2002. "Frequency Effects In Language Processing: A Review with Implications for Theories of Implicit and Explicit Language Acquisition». Studies in Second Language Acquisition 24 (2): 143-188. doi: 10.1017.S0272263102002024.

Ellis, Rod. 1994. The Study of Second Language Acquisition. Oxford: Oxford University Press.

-. 1997. SLA Research and Language Teaching. Oxford: Oxford University Press. 
Fulcher, Glenn i Fred Davidson. 2007. Language Testing and Assessment: An Advanced Resource Book. Nova York: Routledge Applied Linguistics.

Gass, Susan M., i Alison Mackey. 2006. «Input, Interaction and Output: an Overview». AILA Review, 19: 3-17

Herdina, Philip, i Ulrike Jessner. 2002. A Dynamic Model of Multilingualism: Perspectives of Change in Psycholinguistics. Clevedon: Multilingual Matters.

Hymes, Dell H. 1972. «On communicative competence». En Sociolinguistics, editat per John B. Pride i Janet Holmes, 269-293. Baltimore: Penguin Books.

Jessner, Ulrike. 2006. Linguistic Awareness in Multilinguals: English as a Third Language. Edimburg: Edinburgh University Press.

Jiang, Nan. 2002. «Form-meaning mapping in vocabulary acquisition in a second Language». Studies in Second Language Acquisition 24 (4): 617-637.

Krashen, Stephen, i Tracy Terrell. 1983. «Implications of Second Language Acquisition Theory for The Classroom». En The Natural Approach: Language Acquisition in the Classroom, 53-62. Nova York: Phoenix ELT.

Krashen, Stephen. 1981. Second Language Acquisition and Second Language Learning. Òxford: Pergamon Press.

Kroll, Judith i Annette De Groot. 2005. Handbook of Bilingualism. Òxford: Oxford University Press.

Larsen-Freeman, Diane, i Michael H. Long. 1991. An introduction to second language acquisition research. Nova York: Longman.

Lightbown, Patsy i Nina Spada. 2013. How Languages Are Learned. (4th ed.) Òxford: Oxford University Press.

McLaughlin, Barry. 1987. Theories of Second-Language Learning. Londres: Edward Arnold.

Odlin, Terence. 1989. Language Transfer: Cross-Linguistic Influence in Language Learning. Cambridge: Cambridge University Press.

O'Neill, Brittney, Josh Bennett i Chantal Vanier. 2010. «Crossing linguistic boundaries: Making the most of cross-linguistic influence in the language classroom». Working Papers of the Linguistics Circle of the University of Victoria 20 (1): 50-62.

Oxford, Rebecca. 2003. «Language Learning Styles And Strategies: An Overview». En Proceedings of GALA (Generative Approaches to Language Acquisition). http://web.ntpu.edu.tw/ language/workshop/read2.pdf. 
Portolés Falomir, Laura. 2015. Multilingualism and Very Young Learners: An Analysis of Pragmatic Awareness and Language Attitudes. Berlín: Mouton de Gruyter.

Prabhu, N. S. 1987. Second Language Pedagogy. Òxford: Oxford University Press.

Richards, Jack, i Theodore S. Rodgers. 2001. Approaches and Methods in Language Teaching. Cambridge: Cambridge University Press.

Savignon, Sandra J. 2007. «Beyond Communicative Language Teaching: What's Ahead?». Journal of Pragmatics 39 (1): 207220. DOI: 10.1016/j.pragma.2006.09.004.

Selinker, Larry. 1972. «Interlanguage». IRAL - International Review of Applied Linguistics in Language Teaching, 10 (3): 209-232.

Spada, Nina. 2007. "Communicative Language Teaching». En International Handbook of English Language Teaching, editat per Jim Cummins i Chris Davison, 271-288. Boston: Springer US.

Swan, Michael. 1985. «A Critical Look at the Communicative Approach (2)». ELT Journal 39 (2): 76-87.

Upton, Thomas A., i Li-Chun Lee-Thompson. 2001. «The role of the first language in second language reading». Studies in Second Language Acquisition 23 (4): 469-495.

Usó-Juan, Esther, i Alicia Martínez-Flor. 2008. «Teaching intercultural communicative competence through the four skills». Revista Alicantina de Estudios Ingleses 21: 157-170.

Willis, Jane R. 1996. A framework for task-based learning. Essex: Longman. 